\title{
Inferentialism as an alternative to socioconstructivism in mathematics education
}

\author{
Ruben Noorloos ${ }^{1} \cdot$ Samuel D. Taylor ${ }^{2}$. \\ Arthur Bakker $^{1}$ (D) Jan Derry ${ }^{3}$
}

Received: 29 July 2016 / Revised: 9 December 2016 / Accepted: 12 January 2017 /

Published online: 3 February 2017

C) The Author(s) 2017. This article is published with open access at Springerlink.com

\begin{abstract}
The purpose of this article is to draw the attention of mathematics education researchers to a relatively new semantic theory called inferentialism, as developed by the philosopher Robert Brandom. Inferentialism is a semantic theory which explains concept formation in terms of the inferences individuals make in the context of an intersubjective practice of acknowledging, attributing, and challenging one another's commitments. The article argues that inferentialism can help to overcome certain problems that have plagued the various forms of constructivism, and socioconstructivism in particular. Despite the range of socioconstructivist positions on offer, there is reason to think that versions of these problems will continue to haunt socioconstructivism. The problems are that socioconstructivists (i) have not come to a satisfactory resolution of the social-individual dichotomy, (ii) are still threatened by relativism, and (iii) have been vague in their characterization of what construction is. We first present these problems; then we introduce inferentialism, and finally we show how inferentialism can help to overcome the problems. We argue that inferentialism (i) contains a powerful conception of norms that can overcome the social-individual dichotomy, (ii) draws attention to the reality that constrains our inferences, and (iii) develops a clearer conception of learning in terms of the mastering of webs of reasons. Inferentialism therefore represents a powerful alternative theoretical framework to socioconstructivism.
\end{abstract}

Keywords Inferentialism - Socioconstructivism · Mathematics education · Constructivism $\cdot$ Theories of learning

Arthur Bakker

a.bakker4@uu.nl

1 Utrecht University, Utrecht, Netherlands

2 Heinrich Heine University Düsseldorf, Düsseldorf, Germany

3 UCL Institute of Education, London, UK 
The many forms of constructivism have had significant impact on educational theory and practice (Confrey and Kazak 2006; Ernest 1991). A key tenet of constructivism is that knowledge cannot be transmitted in any direct way to students; instead, they construct knowledge themselves based on their experiences and social environment (Clements and Battista 1990). Interest in constructivism has significantly increased in recent decades, judging from the annual number of publications using words starting with constructivis* in the PsycINFO database (see Fig. 1). This increase stands in contrast with the critical analysis of its philosophical underpinnings and educational consequences (Lesh and Doerr 2003; Osborne 1996; Phillips 1995; Roth 2011). There is reason, then, to revisit some of the critical issues given recent developments in philosophy. Bransen (2002) has convincingly argued that inferentialism has much to offer to anyone interested in cognitive development. This article aims to draw lessons for educational theory from inferentialism (Brandom 1994, 2000) and the broader philosophical terrain to which it is connected (e.g., McDowell 1994).

Inferentialism is a semantic theory that explains concept formation in terms of the inferences individuals make in the context of an intersubjective practice of acknowledging, attributing, and challenging one another's commitments. For inferentialism, inferences cannot be understood apart from the norms that exist in this intersubjective practice, the game of giving and asking for reasons, with the consequence that individual reasoning cannot be understood apart from this social, norm-laden game. Inferentialism provides an alternative characterization to constructivism's conception of social-individual interaction that replaces the latter's emphasis on construction with a focus on the role of reasoning in learning (Bakker and Derry 2011; Hußmann and Schacht 2009; Schindler and Hußmann 2013).

The article is structured as follows. We first introduce socioconstructivism, the version of constructivism that in mathematics education seems to be the most accepted one. The following three sections then discuss three problems that we think continue to plague socioconstructivism. These are (i) its problematic conception of the relation

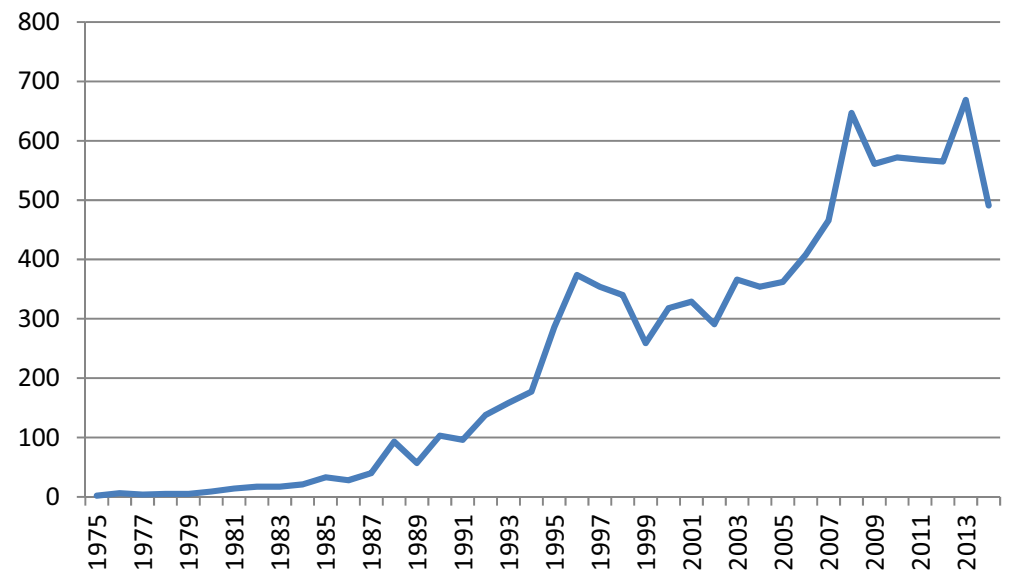

Fig. 1 Number of hits per year when searching for "constructivis*" in PsycINFO 
between the social and the individual, (ii) its lack of an adequate account of the objectivity or world dependence of knowledge, and (iii) the vagueness of the constructivist metaphor. To overcome these problems, we introduce inferentialism as a novel theoretical framework. We are not arguing against the pedagogy of socioconstructivism; instead, our suggestion is that there are problems with its theoretical presuppositions. We first give an introduction to inferentialism, before showing how inferentialism supplies the tools to overcome each of the problems in the next section. We end with a short conclusion.

\section{What is socioconstructivism?}

The term "constructivism" covers a wide and growing range of theories and standpoints. In this article, we limit ourselves to what seems to be the most widely accepted version of constructivism in mathematics education: socioconstructivism. However, where our arguments apply more broadly, we will direct them at constructivism generally. In order to make it clear what we understand by socioconstructivism, we will briefly characterize the main tenets of a typical socioconstructivist position. We aim to illustrate that socioconstructivist positions share two broad orientations. First, they take an intermediate position between cognitive constructivism and sociocultural theories. And second, they combine the elements of these two research traditions in a pragmatic manner. These two orientations, which we will now begin to explain, are sufficient to lay socioconstructivism open to the problems that we describe in the next three sections.

Socioconstructivism was originally developed as a response to a perceived tension between the way the social and individual aspects of learning were theorized (Ernest 1991; Lerman 1996; Steffe and Gale 1995). Socioconstructivism was intended to overcome a dichotomy that many scholars saw between the theoretical perspectives of cognitive constructivism on one hand and sociocultural theories on the other. At its basis, this dispute centers on what constructivist education theorists ought to take to be the primary unit of analysis: the individual or the social. On one extreme, cognitive constructivists, in a neo-Kantian tradition (e.g., Von Glasersfeld 1980), postulated that a constructivist account of learning need only explain the process of learning in terms of the individual's construction of internal knowledge or meaning. This approach concerns itself with the individual's internal cognitive mechanisms and the role they play in helping the learners to make sense of their world. This particular version of constructivism has been influenced by the work of Piaget, who posited a detailed account of the relation between the activity of children and the conception and adjustment of their individual conceptual schemes (Piaget 1970). Whether or not correct (Cole and Wertsch 1996; Confrey 1995; Kitchener 2009), this approach was thought to overemphasize the role of individuals at the cost of their social context and to neglect aspects of learning that were not solely cognitive. In response, some scholars, inspired by Vygotsky (1978), took an opposed position by making the social embedding of learning the primary unit of analysis in place of individual learners' independent constructive activity (Lerman 1996; Mason 2007). Cobb and 
Bowers (1999, p. 5) delineate the tension that arose between these two constructivist approaches by considering two metaphors:

In the case of the cognitive perspective, a central organizing metaphor is that of knowledge as an entity that is acquired in one task and conveyed to other task settings. In contrast, a primary metaphor of the situated learning perspective is that of knowledge as an activity that is situated with regard to an individual's position in the world of social affairs.

This difference in approach has led to a tension in constructivist literature, because, "If from the cognitive point of view, knowing means possessing, from the sociocultural perspective it means belonging, participating, and communicating" (Mason 2007, p. 2). In this sense, the focus in constructivist literature had been either on the "construction of internal knowledge or meaning" or on the "construction [...] of new communities of discourse and social practice" (Kaartinen and Kumpulainen 2002). This is unsatisfactory, because educational theory should surely aim to do justice to both the individual and the social aspects of learning.

Cobb (1994) gave an important impetus to the socioconstructivist program when he argued that these two different perspectives were not contrary to each other but, instead, were complementary. He advocated a "pragmatic" approach which allowed teachers and educationalists to freely combine elements from both perspectives in order to suit their needs. In their seminal paper, Cobb et al. (1992) formulated a socioconstructivist position that was intended to overcome the cognitive-sociocultural divide in this pragmatic manner. Their proposal was to

treat people in general and mathematics teachers and students in particular as active constructors of their ways of knowing and as participants in social practices [...]. Knowing would then be seen as a matter of being able to participate in mathematical practices in the course of which one can appropriately explain and justifying [sic] one's actions. (Cobb et al. 1992, p. 15)

Cobb et al., instead of focusing only on the individual's constructive activity, situate this activity in its social context. They do this by describing it in terms of participation in communal "ways of knowing." In order to avoid postulating a problematic relationship between the student's ideas and an external reality that is independent of human beings, they describe knowledge rather in terms of submitting "taken-as-shared" mathematical constructions in a social practice. In this way, individual mathematical cognition - in the sense of the individual's acquisition of mathematical understanding - is given a social interpretation.

Another example of what we consider to be a representative socioconstructivist position was set out by Vosniadou (2007). Vosniadou's text has the added advantage of being explicitly presented as a middle way between what she calls the "cognitive" and the "situative" perspectives on conceptual change, which correspond to our cognitive and sociocultural perspectives, respectively. Vosniadou argues for "allowing the possibility of objectifying knowledge while considering knowledge acquisition to result 
from participation in sociocultural activities" (Vosniadou 2007, p. 55). In other words, she keeps in place the general cognitivist understanding of knowledge acquisition as a process of theory construction but grounds this process of acquisition in a social context. Vosniadou endorses what she calls "the framework theory approach to conceptual change," which takes learning to result from the development and restructuring of "naïve, intuitive, domain-specific theories constructed on the basis of everyday experience" in both a top-down and a bottom-up manner (Vosniadou 2007, p. 58).

Many other versions of socioconstructivism exist, and it sometimes appears as if there is no clear consensus regarding the meaning of the term. For our purposes, we reiterate that we consider a position to be a socioconstructivist one if it incorporates elements from both the cognitive constructivist and the sociocultural traditions (and if this has been done in a pragmatic way). Having set out our understanding of socioconstructivism, we are now ready to begin considering three enduring problems for socioconstructivism.

\section{The social-individual dichotomy in socioconstructivism}

The first and to our mind most important problem is that, despite the fact that socioconstructivism was explicitly developed to resolve the dichotomy between individual-centric and social-centric approaches to learning, there remains a widespread feeling that it has failed to do this (e.g., Van Oers 2006). Educational theory is still divided by a social-individual dichotomy that dictates both the theory and the practice of education (Akkerman et al. 2007; diSessa 2008; Mason 2007; Mercer 2007). The dichotomy is kept in place by the large differences in the underlying epistemological and metaphorical orientations of the cognitive and sociocultural approaches (Cobb and Bowers 1999; Sfard 1998). Because of this, the question has arisen whether these approaches are simply too disjoint to be reconciled. Will any modification of them be sufficient to adequately theorize both the social and individual aspects of learning (as we should surely attempt to do)?

We would like to consider briefly how the social-individual dichotomy remains unresolved in Cobb et al.'s (1992) article, which we previously cited as an eminent example of a socioconstructivist position (even if it did not yet have that label). Then, we show how the main lines of our criticism of Cobb et al.'s paper apply equally to other socioconstructivist positions. But our argument is not only negative, for we end this section by briefly considering Cobb and Yackel's (1996) attempt to overcome the dichotomy through the introduction of sociomathematical norms, an attempt that we think makes important steps forward.

We previously described Cobb et al.'s position as involving the situating of individuals' constructive activity in a participationist social context. However, is this really sufficient to overcome the social-individual dichotomy? There are reasons to think that it is not, because it is unclear what it would take to overcome this dichotomy. We suggest the following criterion: a theory overcomes the social-individual dichotomy if it can describe the learning activity of the student simultaneously and essentially in both cognitive and social terms. By "simultaneously and essentially," we mean that the theory should be able to describe the activity in such a way that both its social and its cognitive aspects are inseparably connected to it - in other words, the activity would 
not be what it was unless it had both social and cognitive aspects. To use philosophical terminology, these aspects must be "internally related": If either aspect were to be removed, the activity would cease to be. It is not enough, then, for the activity to have both a social and an individual aspect, if it is constituted such that these aspects are not internally related (so that, conceivably, the social or the individual aspect could exist in isolation from the other).

Do Cobb et al. succeed in describing learning activity as simultaneously and essentially both social and cognitive? We believe they do not. For Cobb et al., intersubjectivity turns upon the fact that interpretations of mathematical objects are taken as shared - that is to say, they are not correct in an absolutely objective (realist) manner, but their correctness is based only upon the fact that these interpretations are agreed to be shared by the different participants in the practice, with no way of verifying in an absolute manner whether they are really correct. Here, we do not want to consider the correctness of these interpretations (for this, see the next section), but only the psychological process by which they are constructed, that is, the process of learning. If we consider this process, it becomes clear that Cobb et al. continue to ascribe to the learner, in the tradition of the cognitive constructivists, an ability to construct interpretations of mathematical objects in isolation from her social environment. For it is only when these interpretations already exist that they can begin to be taken as shared. For Cobb et al., sociality is instituted by the individual subjects' taking each others' interpretations of certain problems as shared. Cobb et al. take it that the rejection of the idea that knowledge answers to a reality that is independent of human beings entails that there can be no objective basis for intersubjective agreement, as there is "no way of knowing whether [students'] individual interpretations of a situation actually correspond to those of others" (p. 17), and this, in turn, they take to lead to the view that there is no principled basis for intersubjective agreement at all outside of the pragmatic assumption of shared interpretations. Intersubjectivity is erected on top of individual interpretations and because of this is in a sense still posterior to the constructive activity of the individual. This keeps the socialindividual dichotomy in place.

Cobb et al. do not show why the individual aspect of learning is bound by the social aspect, beyond the fact that observations seems to confirm that it functions that way in practice (Beach 1995; Bowers 1996). For Cobb et al., individual learners have "taken-as-shared mathematical interpretations, meanings, and practices institutionalized by wider society" (p. 16), but there still appears to be an assumption that the individual operates on her own such that individual interpretations come first and social ratification becomes something of a by-product of collective individual interpretative activity. While the process of learning has both individual and social aspects for Cobb et al., the individual dimension remains the basis upon which the social dimension emerges (cf. Radford and Roth 2011). In this way, Cobb et al., like the radical cognitive constructivists, continue to hold on to the idea of an autonomous subject who is able to construct interpretations of mathematical relations in total isolation from her social environment. The social aspects come only later, when the individual interpretations are shared. In this way, the social and the individual aspects of learning, though both are given a place in the wider theory, are still only externally and not internally related. 
We believe that this problem, that the individual and the social aspects of learning, while both accounted for, are kept apart to some extent, is widespread in socioconstructivism. We also find it in Vosniadou's (2007) framework theory of conceptual change. Vosniadou, like Cobb et al., accommodates social aspects of learning, but at the core of her theory is still the individual's ability to construct theories. Although the social environment has an impact on the content of the theories that are developed, it does not impact this theory-forming ability itself. Such a perspective cannot satisfy our overcoming criterion, because by its very nature, it takes the social and individual aspects of learning to be externally and coincidentally, rather than internally, related.

It is worth asking what it would take to effect a genuine overcoming of the social-individual dichotomy. Here, we want to discuss one example that we think moves in the right direction. Cobb and Yackel (1996) introduce the concept of "sociomathematical norms" into their analysis of classroom interactions. These norms "characterize regularities in communal or collective classroom activity and are considered to be jointly established by the teachers and students as members of the classroom community" (p. 178). They explicitly note that "neither the social norms nor the individual students' beliefs are given primacy over the other" ( $p$. 178). Sociomathematical norms are social norms that relate to the teaching of mathematics, for example, "what counts as a different mathematical solution, a sophisticated mathematical solution, an efficient mathematical solution, and an acceptable mathematical solution" (p. 178).

Sociomathematical norms constitute an ontological innovation (diSessa and Cobb 2004) that is reducible neither to the sociocultural nor the cognitive traditions while containing both social and individual aspects. As such, it stands a chance of bringing together the theoretical presuppositions of both of these traditions in a single theoretical tool. It also sets sociomathematical norms apart from attempts to integrate social aspects into a fundamentally individual cognitive process or vice versa. We will have much more to say about norms in what follows. For now, we suggest that Cobb and Yackel's use of norms was not in itself enough to overcome the social-individual dichotomy, because it was still only a part of a broader socioconstructivist attempt to bring the social and cognitive theoretical traditions in sync (see Cobb and Yackel 1996, pp. 459-60). However, from our position, it appears that the notion could have been more successfully applied if it had been given a more central role in the overall theory.

In sum, it is true that socioconstructivist theories cover both the individual and the social aspects of learning. However, they do not reconcile the parts of their theories that are devoted to these two aspects. This often lends their theories a slightly two-sided appearance, as if they theorize not one but two individuals: a "cognitive" individual, modeled on (radical) constructivism, and a "social" individual, modeled on sociocultural theories. This would not be a big problem if it did not mean that, by failing to reconcile the two theories, socioconstructivists also fail to remedy the flawed presuppositions of these theories. In particular, the part of socioconstructivism devoted to the cognitive individual is still a fundamentally isolated individual, to whom, moreover, a fundamentally unconstrained power of construction is ascribed. It is this that underlies the widespread perception that socioconstructivism has not overcome the social-individual dichotomy. However, it appears that a successful overcoming of the social-individual dichotomy may be effected by giving a central role to intersubjective norms. 


\section{The danger of relativism}

A further difficulty for constructivist positions is the question of objectivity (Osborne 1996). To put it succinctly, the central concern is that if all knowledge derives from individual interpretations, we seem to have sacrificed the possibility of objectivity and risk running into the specter of relativism (cf. Boghossian 2006). In some more extreme versions of constructivism, talk of objectivity is rejected in favor of pragmatic notions such as viability (Von Glasersfeld 1980). In Cobb et al. (1992), the main metaphor for knowledge is that of "mathematical ways of knowing" (p. 10), that is, ways of participating in a mathematical social context. Objectivity, on this approach, is assumed to derive from two factors, namely the individual's interpretive activity and her participation in a community of learners.

Many constructivists reject the notion of objective knowledge because they believe that it implies a direct relationship to a world that is outside of human culture and activity, something which they believe to be impossible (Confrey 1995; Wertsch 1985). Yet, it has been argued that such positions continue to misconceive the relation between mind and world and, in fact, implicitly accept the idea they claim to be attacking (Derry 2013). The reason for this is that these positions respond to the perceived impossibility of a genuine mind-world relationship by rejecting the "world" side of this relation entirely and trying to reconstruct a notion of reality on the basis of concepts on the "mind" side of the equation only (such as internal constructions, social interactions, etc.). However, there are good reasons to think that such a one-sided elimination cannot be made to work. For one, such positions run the risk of a misplaced individualism that has the individual learner developing her interpretations "in a void" (McDowell 1994, p. 11). This could also lead to a culturally relativistic account of learning-for example, one in which a particularly recalcitrant community could be justified in constructing $1+1=3$ as a piece of mathematical reasoning.

More fundamentally, however, insofar as they reject the world-related aspects of knowledge, constructivists lose sight of an important dimension of knowledge (McDowell 1994). The problem is not that of accommodating a direct mind-world link that can support a theory of objectivity. Instead, the worry is that constructivists cannot give a role in their theories to reality itself. It appears that for constructivists, the world that we inhabit is no longer a source of knowledge. Rather, knowledge derives solely from individuals' interpretations or social interactions. Although the world may have various forms of impact on our thinking according to constructivists, it does so only through the mediation of our individual interpretations. It is natural, however, to think that our reasoning has to be answerable to the world itself, and constructivists accordingly face the challenge of finding room for this answerability.

\section{What is constructed?}

The third and final problem for constructivism relates to the constructivist metaphor. Evidently, the claim that learning activity takes place through construction of some sort is central to all forms of constructivism. But how does this process take place precisely, and what is its outcome? As Van Oers (2006, pp. 116-7) has pointed out, many constructivists are unclear about this: "they tend to use 'construction' as an explanatory 
concept without having a clear explanation of the nature of this process itself. [...] Instead of using 'construction' as an explanatory concept, 'construction' is above all the concept to be explained."

In our discussion of the social-individual dichotomy, we have already noted that the process of construction for socioconstructivists often remains an individualistic procedure that is unconstrained by outside sources. In this way, an autonomous ability to construct his or her own understanding is ascribed to the student. But, as we have seen above, it is questionable whether the student really possesses such an ability, not least because students grow up in a social environment on which they depend for their cognitive development. Radford and Roth (2011) have argued that describing the activity of learning in terms of construction and related metaphors such as "negotiation," "taken as shared," and "way of knowing" implicitly carries with it an individualistic perspective that denies the impact of the social except insofar as it impacts inner construction from the outside.

There are other problems with the metaphor besides its individualism, however. Most importantly, there is widespread confusion over what it is that is constructed precisely. Suggestions range from "interpretations" and ways of knowing, as in Cobb et al. (1992) and others, to "theories" as in Vosniadou (2007), to, for instance, "knowledge" itself (Scardamalia and Bereiter 2006) or other kinds of socially constructed forms of cognition or understanding. The widespread socioconstructivist vacillation on such a crucial issue seems to betray a deeper uncertainty about what the process of construction is precisely and how it takes place.

Let us illustrate this claim by considering one of the suggestions just mentioned, that of Cobb et al. (1992), in slightly greater detail. Cobb et al. take it that what is constructed is individual students' interpretations of a given subject matter. They also refer to conceptual schemes as outcomes of constructive activity. It appears that a conceptual scheme is the larger mosaic in which a given interpretation must find its place: "The experienced naturalness of certain mathematical interpretations is relative to the taken-as-shared conceptual schemes that we have each actively constructed in the course of our mathematical acculturation." A further term, which specifies the end goal of teaching, is mathematical way of knowing. Cobb et al. continue the previous quote:

As a consequence, we would not characterize teaching as an activity in which we attempt to focus students' attention on things we see in their environment in increasingly explicit ways. Instead, we would view it as an activity in which we guide students' constructive efforts, thereby initiating them into taken-as-shared mathematical ways of knowing. (p. 10)

It would seem that such a way of knowing is a conceptual scheme (or something like it) that has proven useful with respect to a given subject matter. Because it must be taken as shared, it appears to be an individual phenomenon in the first instance. It is unclear if the knowing in question can be reached by an individual (for example, because the way of knowing consistently delivers a pragmatically good solution to problems) or whether it requires intersubjective validation to count as knowing. What is clear, however, is that the way of knowing must be primarily a subjective state, given that it must be taken as shared. 
These three central terms - interpretation, conceptual scheme, and way of knowing - explain little unless supplemented by an account of how they work in connection to actual constructive activity. Cobb et al., however, do not specify how the terms hang together and spend few words on explicating them individually in their original paper. Although they do characterize individual construction as involving intersubjective aspects, still it seems that they simply assume that individuals possess such a capacity to construct interpretations without argument. To some extent, this may reflect epistemological considerations: Given that interpretations are private, it is not possible to directly observe them; thus, Cobb et al. speak of "the inferred quality of the children's experiences" (p. 19; emphasis added). We do not question these epistemological presuppositions. But in order to circumvent a number of ambiguities, it should be made clear, for example, in which different forms the capacity to construct interpretations might manifest itself, to what extent the construction of an individual interpretation requires explicit forethought by the student, and whether or not explicit consideration of the interpretation is required for it to be applied to a given problem. These questions ought to be answered not just to attain a systematic and rigorous theory but also because important aspects of the socioconstructivist's theory of mind would otherwise remain unclear. Progress on questions like these is necessary for Cobb et al.'s position, but also, we think, for other socioconstructivist positions, if they are to come to a more satisfactory description and explanation of the learning process.

\section{Introducing inferentialism}

Having set out three enduring problems for socioconstructivism, we now consider the theoretical framework of inferentialism that we put forward as an alternative.

Inferentialism is a philosophical theory that explains the nature of language in terms of its role in reasoning (see Derry this issue). The meaning of words is explained in terms of their use in social practices. It was developed by the philosopher Robert Brandom (1994, 2000), and this article draws upon his work. However, Brandom's ideas were developed in a context that includes predecessors such as Sellars (Sellars 1997) and contemporaries such as McDowell (McDowell 1994), to whom we will occasionally appeal as a way of clarifying Brandom's ideas. Naturally, we can give only a brief introduction to inferentialism here. We refer interested readers to Brandom's own introduction to his work (Brandom 2000) and to Bransen (2002).

The key idea of inferentialism is that concepts should be understood in terms of their inferential connections (Bakker and Derry 2011). For example, the meaning of "triangle," for Brandom, depends on the fact that one can, inter alia, derive "p's three angles are equal to two right angles" or " $p$ is not a circle" from " $p$ is a triangle," but not "p has four sides." The inferences one can and cannot make on the basis of a given claim articulate what that claim means. So, in learning new inferences that can be made on the basis of "p is a triangle," one is learning more about the meaning of triangle.

Some important features of inferentialism can already be derived from this simple example. For one, it follows that inferentialism endorses semantic holism. That is, it must claim that one cannot learn a concept in one fell swoop; rather, as one becomes gradually familiar with more of the inferences the concept is engaged in, one becomes more familiar with the concept as well. Every concept is related by inferences to other 
concepts (triangle, for example, is related to "angle" and "side"), and one only knows the concept if one is able to make at least some of these inferences correctly. Brandom writes that "one cannot have any concepts unless one has many concepts" (Brandom 2000, p. 15).

Second, because inferences are the rational connections between concepts, it follows that inferentialism emphasizes the role of reasoning (that is, inference-making) in language use. Knowing a concept is being able to reason with it. Perhaps this sounds like a strong and counterintuitive claim at first, as though a thinking process should underlie the use of every word. However, as we explain below, Brandom sees reasoning as primarily a social process of exteriorized linguistic moves, which allows him to develop a much more fine-grained account of reasoning.

The key to this more detailed understanding of reasoning is that Brandom describes the activity of reasoning in terms of a process of social assessment. To see this, it is important to understand the role that (social) norms play in his theory. Brandom couples an inferentialist semantics to a normative pragmatics - that is, he combines an inferentialist conception of the content of concepts with a normative conception of concept use. Inferentialism begins from a conception of social life as pervaded by norms of correctness. In daily life, we humans navigate these norms in all that we do. Reasoning, too, is subject to norms of correctness. Inferences can be correctly or incorrectly made. The inference from " $p$ is an equilateral triangle" to " $p$ contains a right angle," for example, is an incorrect one.

Brandom explains reasoning in terms of social activity broadly in the following way. He conceives of this social activity in terms of a language game in Wittgenstein's sense, though more fundamental. Wittgenstein $(1953, \S 18)$ famously denied language to have a "downtown" - a central language game which is fundamental to all others. For Brandom, however, there is such a downtown: namely, the practice of reason-giving through making assertions. Brandom (2000, p. 189) calls this fundamental linguistic activity the game of giving and asking for reasons. This game consists of the exchange of claims between interlocutors. Normativity is important in this game in that the correctness of what one says in it depends on the reactions of one's interlocutors and one's reaction to those reactions. Others may play a significant role in determining whether what one says is correct. For example, if I first say " $p$ is an equilateral triangle" and then "p contains a 90 degree angle," it is up to others to ask for reasons supporting the claim, which in this case will in effect lead them to sanction me for saying two incompatible things.

Brandom (1994, Chapter 3) develops a wide-ranging and detailed theory that describes the different normative relations that exist in the game of giving and asking for reasons. In outline, the theory is that interlocutors in the game of giving and asking for reasons keep track of each other's utterances in a process that Brandom metaphorically calls deontic scorekeeping. That is, they keep track of the commitments that each makes by "keeping score" of what utterances each of them is allowed or not allowed to make (in line with the general meaning of "deontic" as "relating to duty and obligation"). When someone says something, this is taken as the expression of a commitment. Saying " $p$ is a triangle" commits me to the thought that $p$ is a triangle. In order to converse in the first place, my interlocutor has to keep track of whether I am also entitled to make the claims I make, that is, what other claims I am allowed or not allowed to make based on the claims I have made until now. I may not be entitled to " $p$ 
is a triangle" for several reasons: for example, because I have just said that $p$ has four sides, or because I have not constructed or seen $p$ yet, or because $\mathrm{p}$ is not, in fact (as you but not I know), a triangle, etc. Scorekeeping is following whether my several claims are warranted and assessing my behavior in light of whether it connects rationally to my sayings. Of course, the detailed account here is not consciously recognized when we converse with each other, but it is intended to describe the ways in which we make sense of our interlocutor's utterances in dialog. In dialog, rather than automatically responding to an utterance, we are in effect keeping track of what we each are committing ourselves to and what entitlements follow from our commitments.

The upshot of this theory is that it allows us to give a detailed account of how reason operates in the essentially social game of giving and asking for reasons. In interactions, people test their inferences and their commitments and in this way are able to expand or alter their understanding of the words they use. Because the status of their utterances develops in the context of how they are assessed by others, it is not necessary that an explicit thought process underlies every piece of activity; rather, acts are rational if they make sense to others in connection with the other commitments of the agent. In this way, reasoning is made to be essentially social. At the same time, reason is essential to engaging in the game of giving and asking for reasons, and the social practices that humans engage in should be assessed, according to inferentialism, from the perspective of their rationality. Also, the presence of an interlocutor in basic activity in the game of giving and asking for reason ensures that the individual speaker encounters friction: Her utterances cannot be explained as purely free constructive activity but are actualized in light of how they are received by the interlocutor. The individual's activity cannot be explained outside of the context of participation with others.

A final concept that needs to be introduced is the space of reasons. Sellars, who is one of Brandom's inspirations, had written that

[I]n characterizing an episode or a state as that of knowing, we are not giving an empirical description of that episode or state; we are placing it in the logical space of reasons, of justifying and being able to justify what one says. (Sellars 1997, $\S 36$; his italics)

The space of reasons is the space that one is initiated into when one learns how to think, that is, to engage in the game of giving and asking for reasons. It is worth emphasizing that the fact that knowing can be explained in terms of the space of reasons means that what is involved in knowing is not the subject's ability to construct internal representations which mirror the external world. It is rather the acquisition of a practical mastery over the use of a concept in the game of giving and asking for reasons. Knowing a certain concept is being able to place it in the inferentially structured space of reasons:

To grasp or understand [...] a concept is to have practical mastery over the inferences it is involved in - to know, in the practical sense of being able to distinguish (a kind of know-how), what follows from the applicability of a concept, and what it follows from. (Brandom 2000, p. 48, original emphasis) 
In this way, inferentialism explains the rational use of words in terms of activity in a social practice, namely the game of giving and asking for reasons. Reasoning, which is responding to norms and inferences within the space of reasons, is explained in terms of this mastery.

\section{Inferentialist resolution of the problems}

In this final section, it remains for us to convey the value of inferentialism by indicating how it can overcome the socioconstructivist problems.

\section{The social-individual dichotomy: norms}

Cognitive activity is irreducibly both social and individual in inferentialism. For inferentialism, the most basic form of cognitive activity takes place in cooperation, in the game of giving and asking for reasons. This means that for inferentialism, intersubjectivity is inherent in the reasoning process (Schacht and $\mathrm{Hu} \beta \mathrm{mann}$ 2015). (This is a main point of consensus among the neo-Hegelian theories of which inferentialism is one example; see, for example, Pinkard 1994; McDowell 1994). Only in giving and asking for reasons for one's beliefs can one develop one's beliefs and learn more about them. In inferentialism, a social context is not constructed by a collection of individuals who assume a shared understanding; rather, the individual only comes to exist as a rational being through being inducted into the social space of reasons. It is because individuals learn to cooperate with each other and to hold each other responsible for their claims in the game of giving and asking for reasons that intersubjectivity is established. The establishment of intersubjectivity does not depend on a prior agreement; rather, it consists purely in pragmatically coming to act together. The idea is that speakers can implicitly hold each other accountable in the way required for participation in the game of giving and asking for reasons long before they even gain the ability to explicitly say that they hold each other accountable in this manner. So, the idea of inferentialism is that it is at the level of pragmatic cooperation, rather than at the higher level of agreement, that we need as educators to examine concept use. A postulation of shared understanding would not make sense on an inferentialist picture, precisely because inferentialism rejects as impossible the independence of thought and its articulation in language. It is only on the basis of an intersubjective context that thinking could take place at all - a view in line with Vygotsky's ideas (Bakhurst 2011; Derry 2008, 2013; Sfard 2008).

It is because inferentialism places norms at the heart of human experience that it can avoid the social-individual dichotomy. If we consider the fine structure of rational activity in inferentialism, we see that to the taking up of every normative commitment, there corresponds some reason or inference. That is to say, every reason depends on a social context if it is to be uttered or understood. There are no reasons in the absence of others with whom to discuss, share, or establish them in the first place. The cognitive and the social are therefore internally related in inferentialism, in the sense which we have attempted to define above in our discussion of the social-individual dichotomy. 


\section{The danger of relativism: the game of giving and asking for reasons}

As was discussed above, the danger of relativism is that constructivism must attempt to find a place for reality in its conception of the learning process. Here, too, inferentialism has relevant insights. Brandom, like constructivists, holds that our access to the world is always mediated through our practices. This is because the correctness of our claims is always up to our interlocutors in the game of giving and asking for reasons. However, unlike constructivists, Brandom gives an account of objectivity as well.

Brandom holds that our knowledge claims are answerable to things in the world themselves, despite their being subject to intersubjective normative standards. In brief, this is because, when talking about a triangle, we are purporting to talk about this actual triangle. Even though this claim depends on intersubjective norms both for its correctness and even for its fundamental intelligibility, this does not change the fact that when it is spoken, it has to be assessed depending on whether it correctly speaks of the triangle. That is to say, it is not enough that what the person says about the triangle corresponds with the beliefs other people have about this triangle; instead, it has to correspond with the actual properties of the triangle. By distinguishing between these two different modes of discourse (talk about beliefs and talk about what these beliefs are about), Brandom accommodates the world relatedness of the commitments of participants in the game of giving and asking for reasons. This is despite the fact that inferentialism is primarily intended to be a semantic and not a metaphysical theory. (For more details about Brandom's theory of objectivity, see Brandom 1994, Chapter 8; see also Bransen 2002).

What matters is that Brandom's innovative conception of a social practice, the game of giving and asking for reasons, is such that, despite its being inherently social and based on a pragmatic conception of reasoning and justification, it can still assign an important role to the objectivity and world relatedness of our knowledge claims. In this way, inferentialism shows that the idea that our knowledge claims are constrained by the real world is not incompatible with a rigorous insistence that these claims can exist only in a social context (Derry 2013).

\section{The inferentialist metaphor: reasons and mastering}

Finally, inferentialism replaces socioconstructivism's emphasis on the construction of interpretations with an emphasis on the making and exchanging of reasons. For inferentialism, when students learn a concept, this means that they are learning how to use that concept in making inferences. They are mastering that part of the space of reasons in which the concept is embedded. These reasons and this space are not so much constructed as they are encountered and navigated in the course of classroom activity. Because reasoning, on the inferentialist picture, is always already a social process, it has no place for an individual constructive activity, even if that activity looks to be individually executed. An inferentialist analysis of learning will be focused on the reasons that underlie students' activities, which can be expressed in commitments, actions, or norms. Inferentialism is a philosophical theory without any claims on psychology. Several researchers are currently at work to develop inferential analyses of learning (Bakker and Derry 2011; Hußmann and Schacht 2009; Schindler and Hußmann 2013). 
It is worth noting that just as the cognitive and sociocultural perspectives each have their corresponding metaphorical frameworks, as was famously argued by Sfard (1998), so inferentialism also brings with it its own metaphorical framework. This is the framework of mastering (Taylor et al. submitted). Mastering is the process whereby learners come to grasp practices, including reasoning practices, and hence concepts. By learning to make the correct inferences and exhibit the correct patterns of behavior, they are mastering the reasons and norms that are implicit in these reasoning practices. Mastering, therefore, combines aspects from both the acquisition and the participation metaphors of learning into a new metaphorical framework.

\section{Conclusion}

This article has put forward inferentialism as a powerful theory for mathematics education researchers. We have argued that constructivism, including socioconstructivism, is plagued by a number of recurring problems that inferentialism can overcome. Inferentialism's emphasis on reasoning and norms and its conceptualization of the social aspects of these phenomena are powerful supplements to socioconstructivism.

Socioconstructivism continues to develop and will find new ways of attempting to overcome the problems that we have noted. We have not attempted a comprehensive analysis of all socioconstructivist positions due to limits of space. However, if the analysis of this article is correct, there is reason for thinking that these evolutions will continue to be plagued by the problems that we have noted, such as the separation of individual and community and the threat of relativism that is due to insufficient attention to the external world. Inferentialism, which does give these issues due attention and which in many ways develops an alternative perspective on concepts, can be considered to offer more powerful theoretical resources. Although there is much to be said for the further development of socioconstructivist positions, it has been the purpose of this paper to argue that, in this case, inferentialism offers the possibility of revising some of the long-held assumptions of socioconstructivism concerning the nature of individual meaning-making and the social. In this way, inferentialism represents an alternative theoretical framework to socioconstructivism.

Open Access This article is distributed under the terms of the Creative Commons Attribution 4.0 International License (http://creativecommons.org/licenses/by/4.0/), which permits unrestricted use, distribution, and reproduction in any medium, provided you give appropriate credit to the original author(s) and the source, provide a link to the Creative Commons license, and indicate if changes were made.

\section{References}

Akkerman, S. F., van den Bossche, P., Admiraal, W., Gijselaers, W., Segers, M., Simons, R. J., \& Kirschner, P. A. (2007). Reconsidering group cognition: from conceptual confusion to a boundary area between cognitive and socio-cultural perspectives? Educational Research Review, 2, 39-63.

Bakhurst, D. (2011). The formation of reason. Chichester: Wiley-Blackwell.

Bakker, A., \& Derry, J. (2011). Lessons from inferentialism for statistics education. Mathematical Thinking and Learning, 13, 5-26. 
Beach, K. (1995). Activity as a mediator of sociocultural change and individual development: the case of school-work transition in Nepal. Mind, Culture, and Activity, 2, 285-302.

Boghossian, P. (2006). Fear of knowledge: against relativism and constructivism. Oxford: Oxford University Press.

Bowers, J. S. (1996). Conducting developmental research in a technology-enhanced classroom (doctoral dissertation, Vanderbilt University, 1996). Dissertation Abstracts International, 57, 3433A.

Brandom, R. (1994). Making it explicit: reasoning, representing, and discursive commitment. Cambridge, MA: Harvard University Press.

Brandom, R. (2000). Articulating reasons: an introduction to inferentialism. Cambridge, MA: Harvard University Press.

Bransen, J. (2002). Normativity as the key to objectivity. An exploration of Robert Brandom's Articulating Reasons. Inquiry, 45(3), 373-391.

Clements, D. H., \& Battista, M. T. (1990). Constructivist learning and teaching. Arithmetic Teacher, $38(1), 34$ 35.

Cobb, P. (1994). Where is the mind? Constructivist and sociocultural perspectives on mathematical development. Educational Researcher, 23(7), 13-20.

Cobb, P., \& Bowers, J. (1999). Cognitive and situated learning perspectives in theory and practice. Educational Researcher, 28(2), 4-15.

Cobb, P., \& Yackel, E. (1996). Constructivist, emergent, and sociocultural perspectives in the context of developmental research. Educational Psychologist, 31(3/4), 175-190.

Cobb, P., Yackel, E., \& Wood, T. (1992). A constructivist alternative to the representational view of mind in mathematics education. Journal for Research in Mathematics Education, 23(1), 2-33.

Cole, M., \& Wertsch, J. V. (1996). Beyond the individual-social antinomy in discussions of Piaget and Vygotsky. Human Development, 39(5), 250-256.

Confrey, J. (1995). How compatible are radical constructivism, sociocultural approaches, and social constructivism? In L. Steffe \& J. Gale (Eds.), Constructivism in education (pp. 185-225). Hillsdale, NJ: Lawrence Erlbaum Associates.

Confrey, J., \& Kazak, S. (2006). A thirty-year reflection on constructivism in mathematics education in PME. In A. Gutierrez \& P. Boero (Eds.), Handbook of Research on the Psychology of Mathematics Education: Past, Present and Future (pp. 305-345). Rotterdam: Sense Publishers.

Derry, J. (2008). Abstract rationality in education: from Vygotsky to Brandom. Studies in Philosophy and Education, 27(1), 49-62.

Derry, J. (2013). Vygotsky: philosophy and education. Chichester: Wiley-Blackwell.

Derry, J. (2017). An introduction to inferentialism in mathematics education. Mathematics Education Research Journal.

diSessa, A. A. (2008). A note from the editor. Cognition and Instruction, 26(4), 427-429.

diSessa, A., \& Cobb, P. (2004). Ontological innovation and the role of theory in design experiments. The Journal of the Learning Sciences, 13(1), 77-103.

Ernest, P. (1991). The philosophy of mathematics education. New York: Routledge-Falmer.

Hußmann, S., \& Schacht, F. (2009). Toward an inferential approach analyzing concept formation and language processes. In V. Durand-Guerrier, S. Soury-Lavergne \& F. Arzarello (eds.), Proceedings of the Sixth Congress of the European Society for Research in Mathematics Education (pp. 842-851). Lyon: Institut National de Recherche Pédagogique.

Kaartinen, S., \& Kumpulainen, K. (2002). Collaborative inquiry and the construction of explanations in the learning science. Learning and Instruction, 12, 189-212.

Kitchener, R. F. (2009). On the concept(s) of the social in Piaget. In U. Muller, J. I. M. Carpendale, \& L. Smith, The Cambridge Companion to Piaget (pp. 110-131). Cambridge: Cambridge University Press.

Lerman, S. (1996). Intersubjectivity in mathematics learning: a challenge to the radical constructivist paradigm? Journal for Research in Mathematics Education, 27(2), 133-150.

Lesh, R., \& Doerr, H. M. (Eds.). (2003). Beyond constructivism: models and modelling perspectives on mathematics problem solving, learning, and teaching. New York: Routledge.

Mason, L. (2007). Introduction: bridging the cognitive and sociocultural approaches in research on conceptual change: is it feasible? Educational Psychologist, 42(1), 1-7.

McDowell, J. (1994). Mind and world. Cambridge, MA: Harvard University Press.

Mercer, N. (2007). Commentary on the reconciliation of cognitive and sociocultural accounts of conceptual change. Educational Psychologist, 42(1), 75-78.

Osborne, J. (1996). Beyond constructivism. Science Education, 80(1), 53-82.

Phillips, D. C. (1995). The good, the bad, and the ugly: the many faces of constructivism. Educational Researcher, 24(7), 5-12. 
Piaget, J. (1970). Genetic epistemology. New York: Columbia University Press.

Pinkard, T. (1994). Hegel's phenomenology: the sociality of reason. Cambridge: Cambridge University Press.

Radford, L., \& Roth, W.-M. (2011). Intercorporeality and ethical commitment: an activity perspective on classroom interaction. Educational Studies in Mathematics, 77, 227-245. doi:10.1007/s10649-1001019282-10641.

Roth, W. (2011). Passibility: at the limits of the constructivist metaphor. Dordrecht: Springer.

Scardamalia, M., \& Bereiter, C. (2006). Knowledge building: theory, pedagogy, and technology. In R. K. Sawyer (Ed.), The Cambridge handbook of the learning sciences (pp. 97-118). New York: Cambridge University Press.

Schacht, F., \& Hußmann, S. (2015). Between the social and the individual: reconfiguring a familiar relation. Philosophy of Mathematics Education Journal, 29.

Schindler, M., \& Hußmann, S. (2013). About students' individual concepts of negative integer-in terms of the order relation. In B. Ubuz, C. Haser, \& M. Mariotti (eds.), Proceedings of the Eighth Congress of European Research in Mathematics Education (pp. 373-382). Ankara: Middle East Technical University. http://cerme8.metu.edu.tr/wgpapers/WG2/WG2_Schindler.pdf.

Sellars, W. (1997). Empiricism and the philosophy of mind. Cambridge, MA: Harvard University Press with an introduction by R. Rorty and a study guide by R. Brandom.

Sfard, A. (1998). On two metaphors for learning and the danger of choosing just one. Educational Researcher, $27(2), 4-13$.

Sfard, A. (2008). Thinking as communicating: human development, the growth of discourses, and mathematizing. New York: Cambridge University Press.

Steffe, L. P., \& Gale, J. (Eds.). (1995). Constructivism in education. Hillsdale, NJ: Erlbaum.

Taylor, S. D., Noorloos, R., \& Bakker, A. (forthcoming). Mastering as an inferentialist alternative to the acquisition and participation metaphors of learning. Journal of Philosophy of Education.

Van Oers, B. (2006). An activity theory approach to the formation of mathematical cognition: developing topics through predication in a mathematical community. In J. Maasz \& W. Schloeglmann (Eds.), New mathematics education research and practice (pp. 97-139). Rotterdam: Sense Publishers.

Von Glasersfeld, E. (1980). Radical constructivism. Revue Internationale de Philosophie, 36(4), 612-635.

Vosniadou, S. (2007). The cognitive-situative divide and the problem of conceptual change. Educational Psychologist, 42(1), 55-66.

Vygotsky, L. (1978). Mind in society. Cambridge, MA: Harvard University Press.

Wertsch, J. V. (1985). Vygotsky and the social formation of mind. Cambridge, MA: Harvard University Press. Wittgenstein, L. (1953). Philosophical investigations. Oxford: Blackwell. 